\title{
Stratospheric ozone depletion: a key driver of recent precipitation trends in South Eastern South America
}

\author{
Paula L. M. Gonzalez • Lorenzo M. Polvani • \\ Richard Seager • Gustavo J. P. Correa
}

Received: 22 November 2012/Accepted: 17 April 2013/Published online: 5 May 2013

(C) The Author(s) 2013. This article is published with open access at Springerlink.com

\begin{abstract}
On a hemispheric scale, it is now well established that stratospheric ozone depletion has been the principal driver of externally forced atmospheric circulation changes south of the Equator in the last decades of the 20th Century. The impact of ozone depletion has been felt over the entire hemisphere, as reflected in the poleward drift of the midlatitude jet, the southward expansion of the summertime Hadley cell and accompanying precipitation trends deep into the subtropics. On a regional scale, however, surface impacts directly attributable to ozone depletion have yet to be identified. In this paper we focus on South Eastern South America (SESA), a region that has exhibited one of the largest wetting trends during the 20th Century. We study the impact of ozone depletion on SESA
\end{abstract}

P. L. M. Gonzalez ( $₫)$

International Research Institute for Climate and Society,

Columbia University, 61 Route 9W, 202b Monell, Palisades,

NY 10964, USA

e-mail: gonzalez@iri.columbia.edu

L. M. Polvani

Department of Applied Physics and Applied Mathematics, Columbia University, 500 West 120th Street, S.W. Mudd,

Room 216, New York, NY 10027, USA

e-mail:1mp@columbia.edu

L. M. Polvani

Department of Earth and Environmental Sciences, Columbia University, 500 West 120th Street, S.W. Mudd, Room 216,

New York, NY 10027, USA

L. M. Polvani - R. Seager - G. J. P. Correa

Lamont-Doherty Earth Observatory, Columbia University,

61 Route 9W, Oceanography, Palisades, NY 10964, USA

e-mail: seager@1deo.columbia.edu

G. J. P. Correa

e-mail: gus@1deo.columbia.edu precipitation using output from 6 different climate models, spanning a wide range of complexity. In all cases we contrast pairs of model integrations with and without ozone depletion, but with all other forcings identically specified. This allows for unambiguous attribution of the computed precipitation trends. All 6 climate models consistently reveal that stratospheric ozone depletion results in a significant wetting of SESA over the period 1960-1999. Taken as a whole, these model results strongly suggest that the impact of ozone depletion on SESA precipitation has been as large as, and quite possibly larger than, the one caused by increasing greenhouse gases over the same period.

Keywords Precipitation - Ozone depletion · South America

\section{Introduction}

The depletion of ozone in the polar Antarctic stratosphere (i.e. 'the ozone hole') is now widely recognized to have been a major cause of observed changes in the atmospheric circulation of the Southern Hemisphere (SH) over the last several decades. Thompson and Solomon (2002) originally noted that the ozone holeinduced lower stratospheric temperature trends over the South Pole could be traced all the way to the surface, and suggested that accompanying trends in the geopotential height would result in trends in the surface winds. Modeling evidence (Gillett and Thompson 2003; Perlwitz et al. 2008; Son et al. 2008) has since shown that the wind response to the formation of the ozone hole consists of a southward shift of the eddy-driven, midlatitude jet; in much of the literature, this shift is often 
referred to as a positive trend of the Southern Annular Mode (Thompson et al. 2000).

More recently, using highly-controlled modeling experiments with single forcings, two independent studies have shown that the impact of ozone depletion on the SH in the second half of the 20th Century has actually been considerably larger than the impact associated with increasing greenhouse gases (GHGs) over the same period (McLandress et al. 2011; Polvani et al. 2011a). These modeling results have now received observational confirmation (Lee et al. 2013). Furthermore, the formation of the ozone hole is now believed to have impacts well beyond the middle and high latitudes. As first shown by Son et al. (2009), the ozone hole induced a widening of the summertime Hadley circulation. Accompanying this, summer precipitation increased considerably in the SH subtropics, with the modeled patterns closely resembling those observed over the period 1979-2000, as demonstrated by Kang et al. (2011).

Within the SH subtropics, South Eastern South America (SESA) stands out as a region of great interest: it is now well documented that SESA is one of the areas with the strongest observed 20th Century regional positive precipitation trends in the entire world (Liebmann et al. 2004; Haylock et al. 2006; Barros et al. 2008; Seager et al. 2010). The strong wetting in this region has had a significant economic impact, owing to the subsequent expansion of its agricultural frontiers (Viglizzo et al. 2006; Barros et al. 2008). Understanding the causes of the recent wetting, therefore, is a question of major importance.

The 1960-1999 average December-February (DJF) precipitation over South America is shown in Fig. 1a, with SESA indicated by the black box. This region includes Uruguay, southern Brazil, Paraguay and northern Argentina; and can be thought of as the transition zone between, on one hand, the wetter monsoon core and the South Atlantic Convergence zone and, on the other hand, the drier Andean and Patagonian regions.

In Fig. 1b, we show the linear precipitation trends from 1960 to 1999. SESA stands out as a region of substantial wetting over the second half of the 20th Century, with increases as large as $50 \mathrm{~mm} / \mathrm{month}$ over the 1960-1999 period. Most of the observed annual mean trend is actually explained by the DJF season.

It is illuminating to contrast the DJF and JJA (JulyAugust) time series of precipitation over SESA, which are plotted for the period 1901-2006 on the left and right panels of Fig. 2, respectively. The first thing one notices is a very strong interannual variability in both seasons, creating high vulnerability in the agriculture and water sectors, as well as in the food and electricity productions. It has been established that SESA interannual variability is primarily driven by a strong El Niño-Southern Oscillation (ENSO) teleconnection (e.g., Ropelewski and Halpert 1996), and by the influence of the Indian Ocean Dipole (Chan et al. 2008) and the Southern Annular Mode (Zhou et al. 2001; Silvestri and Vera 2003), albeit to a lesser extent.

In particular, it is immediately clear that the DJF and JJA time series in Fig. 2 are noticeably different after, approximately, 1960. To bring this out we use a flat, dashed, black line in each panel to indicate the 1901-1960 mean. In spite of the large year-to-year variability, SESA precipitation in DJF appears to start rising in the last few decades of the 20th Century, whereas the JJA time series shows no such trend.

Given that (1) the formation of the ozone hole is a major driver of atmospheric circulation changes in the SH over that same period and that (2) the ozone hole effects are largely confined to DJF, Fig. 2 offers the intriguing possibility that stratospheric ozone depletion might have played a major role in the observed SESA precipitation trends. If the recent wetting of SESA were primarily caused by increasing greenhouse gases, it would be difficult to explain why JJA and DJF show different trends.

Consequently, the objective of this paper is to document, using numerical modeling experiments with uniquely specified forcings, whether stratospheric ozone depletion is able to cause substantial wetting over SESA in DJF. Because modeling of precipitation is a difficult matter, we have opted for a multi-model approach. Our strategy is to gather a relatively large number of models, spanning a wide range of complexity, and to document the response of SESA precipitation to ozone depletion in every case. For each model we have analyzed, at least one pair of integrations with and without ozone depletion is available, with all other forcings unchanged. This allows for clear attribution of any modeled SESA precipitation changes to ozone depletion. In several cases, we are actually able to contrast the changes caused by ozone depletion to those caused by increasing greenhouse gases, given that the two forcings were independently specified in some of the models.

As we describe below, we find that all models are in agreement: they show a clear wetting of SESA in response to ozone depletion. Furthermore, while current generation models are unable to quantitatively simulate the magnitudes of the observed SESA trends, they consistently show that the response of SESA precipitation to ozone depletion is larger than the one accompanying GHG increases. And, 
Fig. 1 GPCCv4 DJF precipitation over South America for the period 1960-1999. a Time mean precipitation over that period, with a $100 \mathrm{~mm} /$ month contour interval. b Linear trends over the same period, with the thick black showing the zero contour, and additional contours at -25 and $25 \mathrm{~mm} / \mathrm{month}$ intervals. The magenta dots indicate grid points were the linear trend is significant at the $90 \%$ level, according to a Mann-Kendall test. In both panels, the black box shows our definition of SESA

GPCCv4 DJF Precipitation 1960-1999

(a) Mean
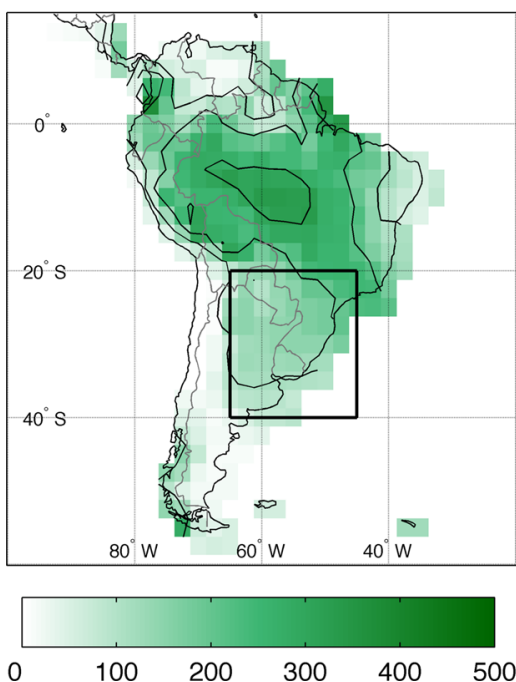

(b) Change

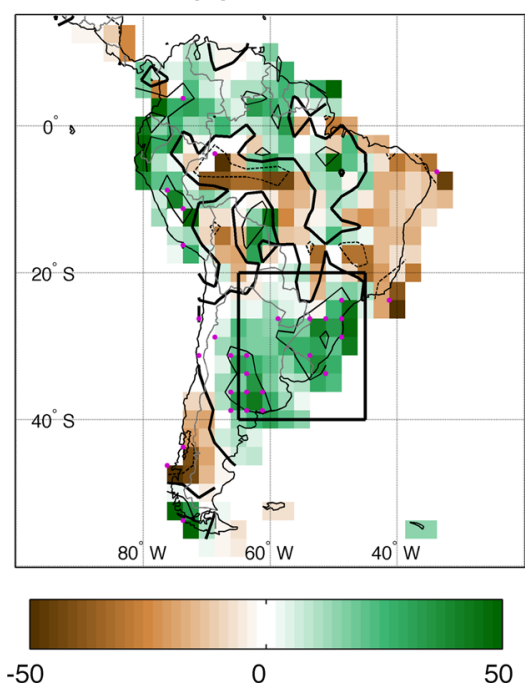

GPCCv4 SESA precipitation
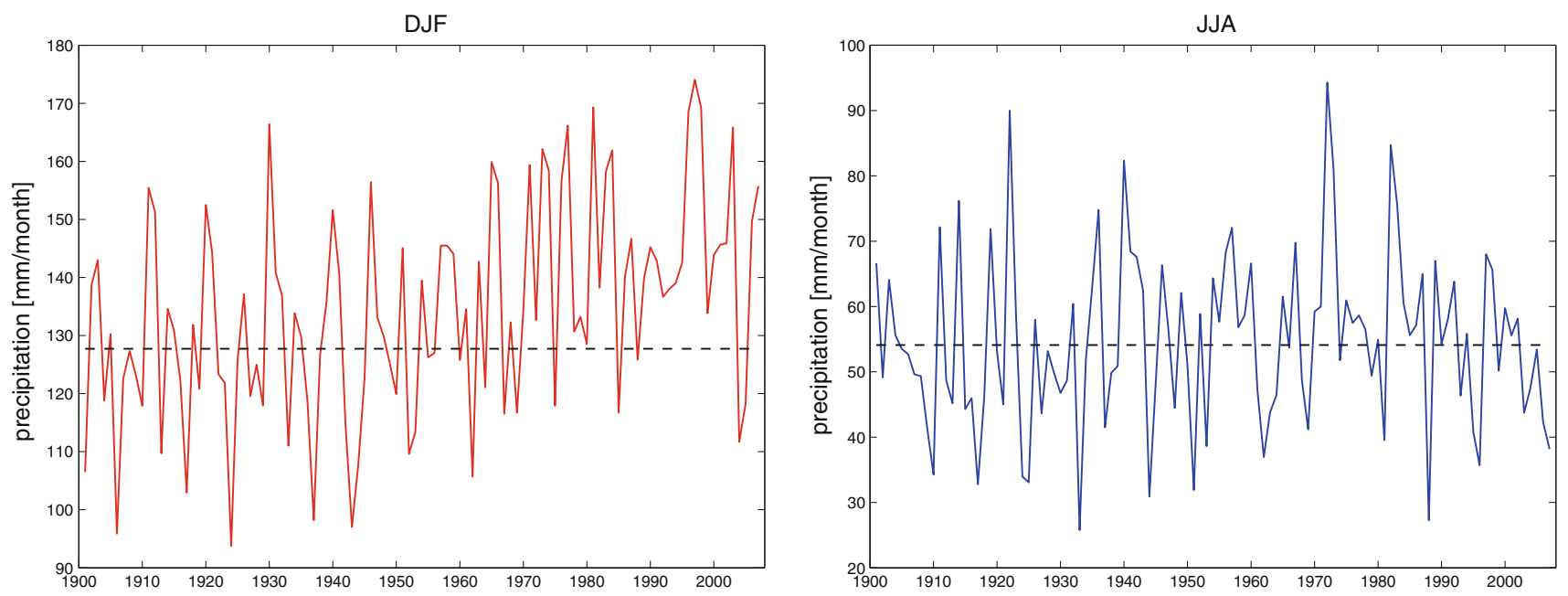

Fig. 2 GPCCv4 precipitation time series, averaged over the SESA region, for (left) DJF and (right) JJA, in the period 1901-2007. The dashed black line indicates the 1901-1960 mean value

finally, we demonstrate that SESA precipitation changes related to the formation of the ozone hole can, in the models we have analyzed, be almost entirely attributed to atmospheric circulations changes, in accordance with previous work (Kang et al. 2011).

In the remainder of the paper, these results will be discussed as follows. In Sect. 2, we present in detail the modeling output we have analyzed in this study, documenting both the model characteristics and the forcing configurations used. The main results, i.e., the response of SESA precipitation to ozone depletion in each model, are represented in Sect. 3, and the dynamical mechanism for this response is illustrated in Sect. 4. A brief summary closes the paper.

\section{Data and methods}

For simplicity and reproducibility of our work, we define SESA as the land area comprised between $40^{\circ} \mathrm{S}$ and $20^{\circ} \mathrm{S}$ in latitude and between $65^{\circ} \mathrm{W}$ and $45^{\circ} \mathrm{W}$ in longitude. We apply this definition uniformly across all observational and model datasets analyzed in this paper.

Since the primary objective of this study is assessing the impact of stratospheric ozone depletion on SESA precipitation, we will focus on the period 1960-1999, when most of the ozone hole formation occurred and during which a strong and statistically significant precipitation trend is observed. For the same reason, we limit our analysis to the summer months from December to February (DJF); it is 
well documented that, while the ozone minimum occurs in October, a lag is needed for the signal to reach the surface (e.g., Polvani et al. 2011a). Models show no response to ozone depletion during JJA, consistent with the lack of an ozone hole in that season. In addition, the largest precipitation trends in SESA have been observed in DJF.

\subsection{Observations}

We use observed precipitation data from WMO/DWD Global Precipitation Climatology Centre monthly dataset, version 4 (hereafter GPCCv4, Schneider et al. 2008). This dataset covers the period 1901-2007, and is available at spatial resolutions of $0.5,1.0$ and 2.5 degrees. Its main advantage rests in having been shown to reproduce SESA summer precipitation variability in good agreement with long station-based records over that region (Gonzalez et al. 2012). Throughout this study, we will use the $2.5^{\circ}$ resolution dataset only, which is closer to the resolution of most of the model output analyzed here.

\subsection{Model integrations}

In order to build a strong case for the impact of ozone depletion on SESA precipitation, and given the intrinsic difficulty of modeling rainfall, we have opted to show a maximum of modeling evidence. To this end, we have taken the somewhat unusual approach of assembling into one paper nearly all currently available, pertinent, model output from a number of relevant studies that have recently appeared in the literature, and some additional, unpublished experiments. Specifically, we have included here all recent models for which integrations with and without ozone depletion are available, with forcings typical of the late 20th Century.

The advantage of this approach is that the evidence presented will come from a very wide range of models, from 'low-top' atmospheric general circulation models (AGCMs) with specified sea surface temperatures (SSTs) to 'high-top' (i.e. stratosphere resolving) coupled atmosphere-ocean models (CGCMs) with fully interactive stratospheric chemistry.

In this section we briefly document the models and the specific integrations we have analyzed, with the latter summarized in Table 1. Additionally, we reference companion papers that can be found in the extant literature documenting in detail the individual models and the corresponding forcings.

\subsubsection{Time-slice integrations}

The simplest type of model output we have analyzed is in the form of so-called 'time-slice' integrations. In this configuration, models are forced with seasonally varying ozone concentrations and sea surface temperatures (if needed), but with no year-to-year trends. To evaluate the response of the climate system to ozone depletion, an initial 'reference' integration (many decades long) is performed, with ozone levels typical of conditions before the formation of the ozone hole. The 'perturbed' integrations are then carried out (also many decades long) with ozone levels typical of the decade 2000-2010, where a considerable ozone hole is present over Antarctica in SH spring. The response of the climate system to ozone depletion (or other forcings) is then computed as the difference in the climatologies between the perturbed and the reference integrations.

Two sets of previously published time-slice integrations are analyzed here: one from the Community Atmospheric Model, version 3, and the other from the Canadian Middle Atmosphere Model. A brief description of each set follows. a. CAM3 time-slice integrations. The simplest model integrations we have analyzed were performed with the Community Atmospheric Model, version 3 (CAM3), documented in Collins et al. (2006). For these experiments, CAM3 was run with T42 horizontal resolution and 26 hybrid vertical levels, only 8 of which are located above $100 \mathrm{hPa}$. The model top being at $2.2 \mathrm{hPa}$, CAM3 can be referred to as a low-top model, in which the stratospheric circulation is poorly resolved. The SSTs were specified from Rayner et al. (2003), while the ozone fields were taken from Cionni et al. (2011).

In addition to 50-year long 'reference' integrations, in which all forcings were specified at year 1960 levels, three perturbed 50-year long runs were analyzed. One with all forcings set at year 2000 levels ('all-forcings'); one with GHGs and SSTs set at year 2000 levels, but ozone kept at year 1960 levels ('GHG-only'); and, lastly, one in which all forcings were kept at 1960 levels except for ozone, which was set at the year 2000 levels ('ozone-only'). Additional details can be found in Polvani et al. (2011a). b. CMAM time-slice integrations. The second set of model integrations were carried out with the Canadian Middle Atmosphere Model (CMAM), a coupled atmosphere-ocean model that extends so as to encompass the entire middle atmosphere, as detailed in Scinocca et al. (2008). For the integrations analyzed here, the model was run with T63 horizontal resolution and 71 vertical levels, reaching approximately a height of $100 \mathrm{~km}$. This is, therefore, a high-top model, with a good resolution of stratospheric dynamics and its variability. The atmospheric chemical composition is entirely specified in this version of CMAM, with the ozone concentration taken from Randel and Wu (2007). The other main difference from CAM3 is that CMAM is a fully coupled atmosphere-ocean model. 
Table 1 Descriptions of the model output analyzed in this paper and the experimental design

\begin{tabular}{|c|c|c|c|c|c|}
\hline Type & Model & Resolution & Reference paper & $\begin{array}{l}\text { \# integration } \\
\text { name }\end{array}$ & Brief description \\
\hline \multirow[t]{8}{*}{ Time-slice } & \multirow[t]{4}{*}{ CAM3 } & \multirow[t]{4}{*}{$\begin{array}{l}\text { T42 L26 } \\
\text { (low top) }\end{array}$} & \multirow[t]{4}{*}{ Polvani et al. (2011a) } & 1 reference & $\begin{array}{l}50 \text { years, steady forcings @ } 1960 \text { levels, } \\
\text { SSTs from obs }\end{array}$ \\
\hline & & & & 1 all-forcings & $\begin{array}{l}\text { As reference, but all forcings at @ } 2000 \\
\text { levels }\end{array}$ \\
\hline & & & & 1 GHG-only & $\begin{array}{l}\text { As reference, but GHGs \& SSTs @ } 2000 \\
\text { levels }\end{array}$ \\
\hline & & & & 1 ozone-only & As reference, but $\mathrm{O}_{3} @ 2000$ levels \\
\hline & \multirow[t]{4}{*}{ CMAM } & \multirow[t]{4}{*}{$\begin{array}{l}\text { T63 L71 } \\
\text { (high top) }\end{array}$} & \multirow[t]{4}{*}{ Sigmond et al. (2010) } & $\begin{array}{l}1 \text { reference } \\
(\mathrm{CGCM})\end{array}$ & $\begin{array}{l}80 \text { years, steady forcings @1979 levels, } \\
\text { coupled model }\end{array}$ \\
\hline & & & & $\begin{array}{l}3 \text { ozone-only } \\
\text { (CGCM) }\end{array}$ & As CGCM reference, but $\mathrm{O}_{3} @ 2005$ levels \\
\hline & & & & $\begin{array}{l}1 \text { reference } \\
(\mathrm{AGCM})\end{array}$ & $\begin{array}{l}\text { As CGCM reference, atmosphere only } \\
\text { (SSTs from reference) }\end{array}$ \\
\hline & & & & $\begin{array}{l}1 \text { ozone-only } \\
\text { (AGCM) }\end{array}$ & As AGCM reference, but $\mathrm{O}_{3} @ 2005$ levels \\
\hline \multirow[t]{3}{*}{ Transient } & \multirow[t]{3}{*}{ CAM3 } & \multirow[t]{3}{*}{$\begin{array}{l}\text { T42 L26 } \\
\text { (low top) }\end{array}$} & \multirow[t]{3}{*}{$\begin{array}{l}\text { Unpublished, but similar to } \\
\text { Polvani et al. (2011a) }\end{array}$} & 40 all-forcings & $\begin{array}{l}\text { 1950-2009, all forcings transient, SST } \\
\text { from obs }\end{array}$ \\
\hline & & & & 40 GHG-only & 1950-2009, only $\mathrm{O}_{3}$ transient \\
\hline & & & & 40 ozone-only & 1950-2009, only GHGs and SSTs transient \\
\hline \multirow{3}{*}{$\begin{array}{l}\text { CMIP5 } \\
\text { transient }\end{array}$} & \multirow[t]{3}{*}{ CCSM4 } & \multirow{3}{*}{$\begin{array}{l}\sim 1^{\circ} \mathrm{L} 26 \\
\quad(\text { low top })\end{array}$} & \multirow[t]{3}{*}{ Gent et al. (2011) } & 5 all-forcings & 1850-2005, all forcings transient \\
\hline & & & & 3 GHG-only & $\begin{array}{l}\text { Fixed } 1850 \text { forcings, but transient GHGs } \\
1850-2005\end{array}$ \\
\hline & & & & 3 ozone-only & $\begin{array}{l}\text { Fixed } 1850 \text { forcings, but transient } \mathrm{O}_{3} \\
\quad 1850-2005\end{array}$ \\
\hline \multirow[t]{6}{*}{$\begin{array}{l}\text { CCMVal-2 } \\
\text { transient }\end{array}$} & \multirow[t]{3}{*}{ WACCM } & \multirow[t]{3}{*}{$\begin{array}{l}\sim 2^{\circ} \text { L66 } \\
\quad(\text { high top) }\end{array}$} & \multirow[t]{3}{*}{ Garcia et al. (2007) } & 3 all-forcings & $\begin{array}{l}\text { 1960-2100, all forcings transient, modeled } \\
\text { SSTs (REF-B2) }\end{array}$ \\
\hline & & & & 1 GHG-only & $\begin{array}{l}\text { As REF-B2, but halogens @ } 1960 \text { levels } \\
\text { (SCN-B2b) }\end{array}$ \\
\hline & & & & 1 ozone-only & $\begin{array}{l}\text { As REF-B2, but GHGs and SSTs @ } 1960 \\
\text { levels (SCN-B2b) }\end{array}$ \\
\hline & \multirow[t]{3}{*}{ CMAM } & \multirow[t]{3}{*}{$\begin{array}{l}\text { T31 L71 } \\
\text { (high top) }\end{array}$} & \multirow[t]{3}{*}{ McLandress et al. (2010) } & 3 all-forcings & $\begin{array}{l}\text { 1960-2100, all forcings transient, coupled } \\
\text { GCM (REF-B2) }\end{array}$ \\
\hline & & & & 3 GHG-only & $\begin{array}{l}\text { As REF-B2, but halogens @ } 1960 \text { levels } \\
\text { (SCN-B2b) }\end{array}$ \\
\hline & & & & 3 ozone-only & $\begin{array}{l}\text { As REF-B2, but GHGs and SSts @ } 1960 \\
\text { levels (SCN-B2c) }\end{array}$ \\
\hline
\end{tabular}

In the fifth column, the name of each ensemble is preceeded by the number of integrations with identical forcings (i.e. the ensemble size)

The integrations analyzed here have been presented and discussed in Sigmond et al. (2010). They consist of four 80 -year long integrations of the CGCM. The 'reference' run has monthly varying and zonally symmetric ozone concentrations fixed at the year 1979 (the pre-ozone hole state). Additionally, three 'ozone-only' integrations are identical to the 'reference', except the ozone concentrations were changed to the severely depleted 2005 levels. In addition to these coupled integrations, a pair of 80-year integrations ('reference' and 'ozone-only') were performed with the atmospheric component of the model alone, for which the SSTs were specified from the corresponding coupled integrations above. We label these with 'AGCM' to distinguish them from the CGCM runs.

For clarity, we point out that these CMAM time-slice integrations, for which no GHG-only experiment is available, are included in the analysis to complement the assessment of stratospheric ozone depletion.

\subsubsection{CAM3 transient integrations}

The next step in model complexity is given by a low-top AGCM (CAM3) with time-varying forcings over the second half of the 20th Century. These integrations are the 
only ones analyzed in this paper which have not been presented in prior publications, although they are very similar to the CAM3 time-slices. Specifically, identical CAM3 configuration and forcing dataset were used as in Polvani et al. (2011a), except that the forcings vary continuously from 1960 to 2000 .

Since these are transient runs, there is no need for a 'reference' integration. Three ensembles of integrations were performed in transient mode: their names-'allforcings', 'GHG-only' and 'ozone-only' - are self explanatory. Each ensemble has 40 members, constituting the largest set analyzed in this paper.

\subsubsection{CCSM4/CMIP5 transient integrations}

From transient runs with an atmosphere-only model (CAM3), we next consider transient runs with a coupled atmosphere-ocean model (with land surface and sea-ice components), the Community Climate System Model, version 4 (CCSM4). This is one of the models used by the National Center for Atmospheric Research (NCAR) to produce simulations for the Climate Model Intercomparison Project, Phase 5 (CMIP5). For the output analyzed here, the resolution of the model atmosphere was $1.25^{\circ}$ longitude by $0.9^{\circ}$ latitude (called ' $1^{\circ}$ version'), with 26 vertical levels (a low-top model); this was coupled to the Parallel Ocean Program version 2 (POP2), as described by Smith et al. (2010). Further details about the CMIP5 configuration of CCSM4 can be found in Gent et al. (2011).

At the time of this analysis, CCSM4 output produced for the CMIP5 project was available for both the historical and single forcing integrations over the period 1850-2005. The forcings for these integrations follow the CMIP5 protocol (Taylor et al. 2012). Specifically, we have analyzed the follow integrations:

- 'all-forcings': these are CCSM4/CMIP5 historical integrations, which include all the transient forcings. An ensemble of 5 such integrations is available.

- 'GHG-only': only the GHGs concentration are transient, with all other forcings fixed at 1850 levels. An ensemble of 3 such integrations is available.

- 'ozone-only': only the ozone forcing is transient, as described in Lamarque et al. (2010). All other forcings are fixed at 1850 levels. An ensemble of 3 such integrations is available.

\subsubsection{CCMVal-2 transient integrations}

Last in order of complexity, we analyzed several sets of integrations that were performed as part of the Stratospheric Processes and their Role on Climate (SPARC) Chemistry-Climate Model Validation phase 2 (CCMVal-2) project, described in SPARC (2010). For these integrations, state-of-the-art chemistry-climate models were used. In brief, these are high-top models (with good resolution of the stratospheric circulation) and with interactive stratospheric chemistry (e.g., Morgenstern et al. 2010). Such models are typically used for the scientific assessments of ozone depletion (WMO 2010). Output from two such models was analyzed in this paper: the Whole Atmosphere Community Climate Model (WACCM) and the Canadian Middle Atmosphere Model (CMAM). A brief description of each set follows.

a. WACCM The version of the Whole Atmosphere Community Climate Model used for the integrations analyzed here is fully described in Garcia et al. (2007). WACCM was run at $1.9^{\circ}$ by $2.5^{\circ}$ horizontal resolution, with 66 vertical levels, and a model top at about $150 \mathrm{~km}$. In addition to interactive stratospheric chemistry, this version of WACCM also includes many upper atmosphere processes (e.g., ion chemistry in the mesosphere, auroral processes, etc). Finally, we note that this version of WACCM was run with specified SSTs, which were taken from model output from CMIP3 integrations.

b. CMAM The version of CMAM used here is quite similar to the one described in Sect. 2.2.1 above. There is one key difference: this version was integrated with interactive stratospheric chemistry. Because of the computational cost associated with the chemistry component, the horizontal resolution was reduced to T31, with the model top at $0.00081 \mathrm{hPa}$. Compared to WACCM, these CMAM integrations have the advantage of being fully coupled to the NCOM 1.3 ocean general circulation model. This model configuration, and the associated integrations described below, are documented in McLandress et al. (2010). The chemistry-coupled version of CMAM is, in terms of complexity, the most comprehensive of the models we have analyzed.

For both WACCM and CMAM, we have analyzed three ensembles of model integrations. These are:

- 'all-forcings': these integrations, over the period 1960-2100, are meant to cover the past and extend into the future, using forcings from the SRES A1B scenario. To insure continuity between the past and future, these integrations do not include solar variability and volcano activity, but they do include all anthropogenic forcings. The SSTs are either specified from another model (in the case of WACCM), or are part of the model itself (in the case of CMAM). For reference, these integrations were labeled 'REF-B2' in the CCMVal-2 project. Further details can be found in Sect. 2.5 of the SPARC Report (SPARC 2010).

- 'GHG-only': these integrations are identical to the allforcings ones above, but with surface halogen 
concentrations fixed at the 1960 (i.e.; at pre-ozone hole) levels. In these integrations, no ozone hole forms over the South Pole. These integrations were labeled 'SCNB2b' in the CCMVal-2 project.

- 'ozone-only': these integrations are identical to the allforcings ones, but with GHGs and all other forcings fixed at the 1960 levels; specifically, the SSTs are taken as the 1955-1964 average of the REF-B2. They were labeled 'SCN-B2c' in the CCMVal-2 project.

\subsection{Calculating the change due to ozone depletion} and its significance

In summary (see Table 1), we have studied 6 sets of model configurations: two sets of time-slice integrations (a lowtop AGCM and a high-top CGCM), and four sets of transient runs (a low-top AGCM, a low-top CGCM, and two with high-top chemistry coupled models).

For every model, we are interested in documenting the response of SESA precipitation to external forcings. In order to quantitatively compare model output from the time-slice and transient integrations, we compute the 'change' in precipitation, which we define as follows. For the time-slice integrations, it is simply the difference between the perturbed and reference integrations, pro-rated by the length of the run. For instance, for the CMAM timeslice integrations (see Sect. 2.2.1.b above), the forcing period (in terms of ozone depletion) is somewhat smaller (1979-2005) than in the other models (1960-1999); so we compute the change for 1979-2005, in $\mathrm{mm} /$ month for a 27-year period, and then we re-scale it for a 40 -year period, to get a precipitation change commensurate with the other models. For all the transient integrations, the 'change' is constructed by first computing the linear trend from 1960 to 1999 , and then multiplying it by 40 years.

In the case of the time slices, the statistical significance is assessed using a $t$ test as in Kang et al. (2011). When more than one time-slice is available for a same experiment, they are considered as a single concatenated run. For the transient integrations, the statistical significance of the linear trend for the period 1960-1999 is assessed using a Mann-Kendall test (Mann 1945; Kendall 1975). When multiple ensemble members were available, the significance test was applied to the ensemble mean.

\section{Modeled SESA precipitation changes}

\subsection{The CMIP simulations}

Prior to describing the effect of ozone depletion on SESA precipitation for the models in Table 1, it is important to consider how recent generations of state-of-the-art climate models simulate the observed SESA precipitation changes over the ozone hole formation period. To this end, we have analyzed both the CMIP3 and CMIP5 models, and the results are shown in Fig. 3.

Each panel presents both the individual and the multimodel mean for 1960-1999 changes over SESA. The values in the top panel are for the CMIP3 models for which we used the '20C3M' simulations (Meehl et al. 2007). In the bottom panel we show the CMIP5 results, for which we have used the 'historical' simulations (Taylor et al. 2012).

The key point to be made from this figure is that the CMIP multi-model means (grey bars) severely underestimate the observed precipitation trends (black bars) over SESA. For the CMIP3 models (top panel), this was already noted in Seager et al. (2010), although we are here specifically focusing on the last four decades of the 20th Century, when the largest trends are observed. The lower panel of Fig. 3 confirms that the same remains true for the CMIP5 trends.

There is some indication in Fig. 3 that the CMIP5 models agree better with the observations than the CMIP3 models, although the multi-model mean precipitation trend in the latest CMIP is still smaller than that in the observations-by more than a factor of 5. Closer inspection reveals that just a few models (i.e., GFDL-CM3 and HadGEM2-ES) account for most of the increase in the multi-model trend; note also that 8 of the 26 models in the ensemble still produce negative trends.

The blue bars in Fig. 3a show two subsets of CMIP3 models, with and without ozone depletion specified. As documented in Son et al. (2009), approximately half the models in CMIP3 did not include the formation of the ozone hole as a forcing in the $20 \mathrm{C} 3 \mathrm{M}$ simulations. Comparing the two blue bars in Fig. 3a (left: fixed ozone; right: varying ozone) appears to suggest, however, that ozone depletion does not have a significant effect on SESA precipitation. Such a conclusion, however, would be premature, since many other forcings differ between the two sets of simulations. See, as a cautionary example, the recent commentary of Previdi and Polvani (2012) on $\mathrm{Hu}$ et al. (2011).

For the CMIP5 historical simulations, all modeling groups were asked to include ozone depletion as part of the 20th Century forcings (Taylor et al. 2012), although the actual ozone forcings were not uniquely specified, and therefore differ greatly (Eyring et al. 2012). Since no CMIP5 models lack ozone depletion, one cannot carry out an exercise similar to the one we have just discussed for CMIP3. We have, however, attempted to see if one may be able to document the importance of a well-resolved stratosphere by segregating the high-top and low-top models in CMIP5, following Gerber et al. (2012). As 
Fig. 3 Changes in SESA precipitation in state-of-the-art CGCMs for the period 1960-1999. a 'run1' from the 20C3M CMIP3 simulations.

Model with an asterisk did not include time-varying ozone concentrations. b run 'r1ilp1' from the historical CMIP5 simulations. The letters $L, M$, and $H$ after the model name indicate the relative vertical resolution of the model: low, middle and high, respectively. In both panels the black bar shows the observed change, from the GPCCv4 dataset, and the grey bars show the multimodel ensemble mean. When present, the thin black lines represent 1 standard deviation from the inter-model spread.

The number between parenthesis represents the size of the model ensemble for each group
SESA DJF precipitation change (1960-1999)

(a) CMIP3 20c3m (run 1) vs. observations

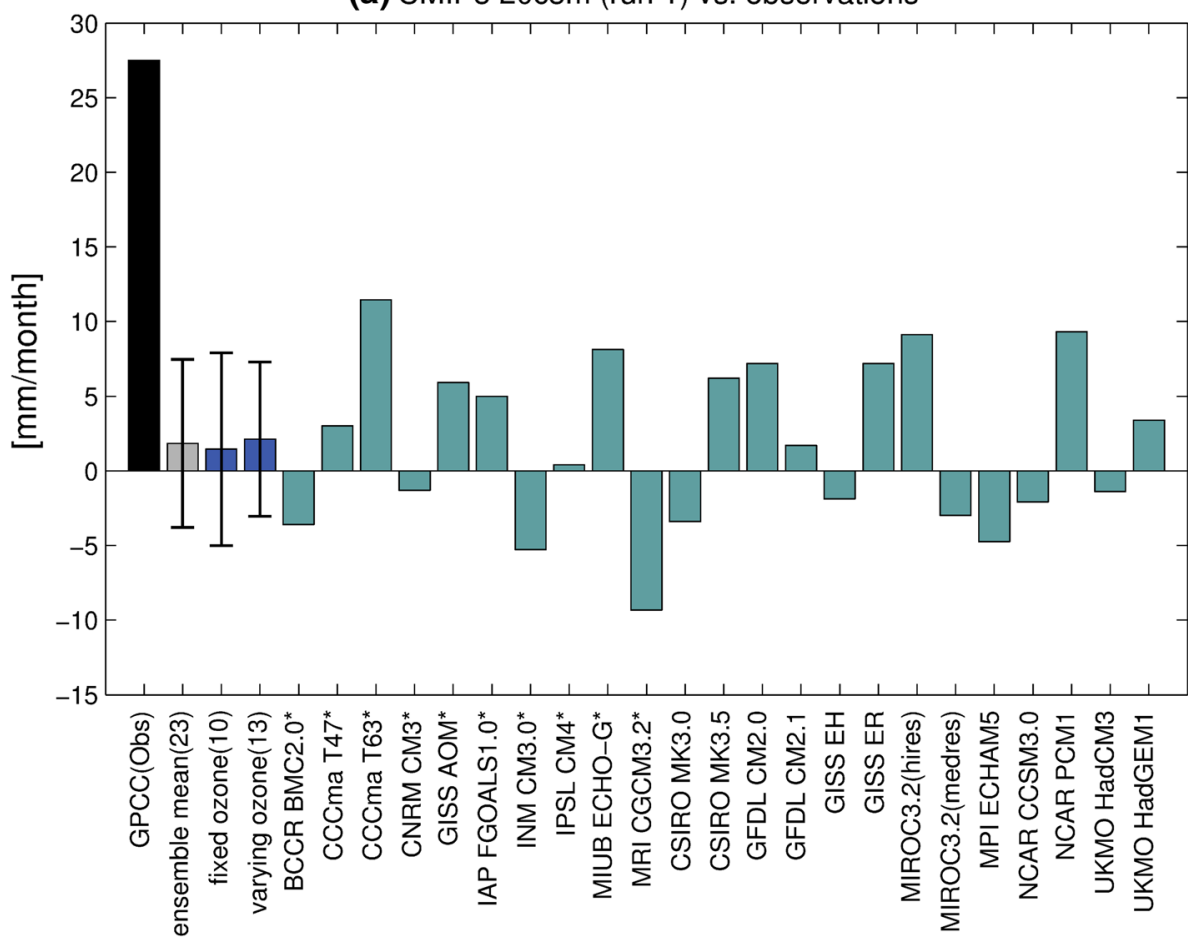

(b) CMIP5 historical (r1i1p1) vs. observations

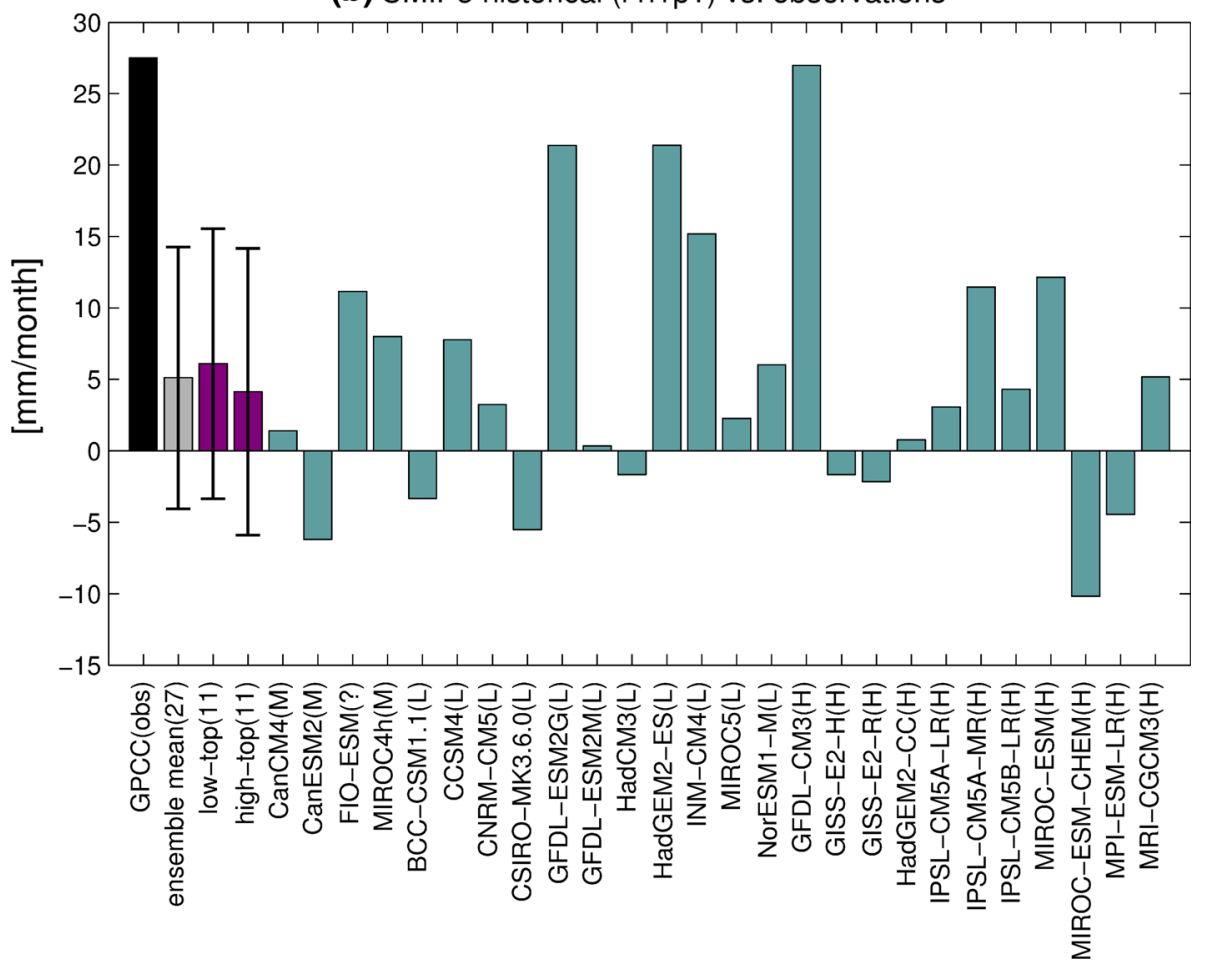

shown by the blue bars in Fig. 3b, it would appear that the low-top models are slightly closer to the observations. This, however, would be a premature conclusion, since other differences exist between the two sets of models.
Difference in SESA precipitation trends cannot be attributed to model top alone from the CMIP5 ensemble.

From this discussion we therefore conclude that the CMIP model output is the wrong tool to assess the impact 
of ozone depletion on SESA precipitation. This is why we have decided to analyze sets of models where a single forcing is changed at a time. We consider this to be a rigorous way to study cause and effect relationships using climate models.

\subsection{The time-slice integrations}

\subsubsection{The CAM3 time-slice integrations}

In order to assess the importance of ozone depletion from the simplest to the most complex models, we start by discussing SESA precipitation changes in the low-top, CAM3 time-slice integrations of Polvani et al. (2011a). For this model, three perturbed integrations are available (GHG-only, ozone-only and all forcings), all of which can be contrasted to the reference integration.

Before studying precipitation changes, we wish to evaluate how well CAM3 reproduces the climatological DJF precipitation over South America. Since we have only time slice integrations, a field that can be compared directly with Fig. 1a, which shows the 1960-1999 mean, is constructed by averaging the reference and the all-forcings integrations. This is shown in Fig. 4a. Comparing with GPCCv4, one can see that the monsoon-related precipitation is well represented in this model, and the South Atlantic Convergence Zone (SACZ) shows an orientation consistent with the observations (see Fig. 1a). However, the mean precipitation in SESA appears to be underestimated, especially in its southern half.

The precipitation change for the all-forcings integration shows a clear wetting over most of SESA (Fig. 4b), in agreement with observations. The overall spatial pattern of the change over South America, however, shows significant differences from the observed pattern (Fig. 1b), especially north of $20^{\circ} \mathrm{S}$. In particular, the eastern Brazilian coast shows wetting, which is opposite to the observed change. Analogous problems are found to the north of the equator.

The GHG-only integration (Fig. 4c) shows a very similar spatial pattern, in the tropical region, to that in the allforcings case. This suggests that those patterns are mainly due to the increase in GHGs. Over the SESA box, however, the modeled changes are mainly negative, whereas in the observations they are mostly positive (see Fig. 1b). We conclude that GHGs are unable to produce the observed wetting of SESA in this model.

In contrast, the ozone-only integration (Fig. 4d) shows a spatially-coherent-albeit small-wetting over SESA. Since the prominent dipolar feature over eastern Brazil (which one can see in the all-forcings case, Fig. 1b) is absent in the ozone-only integration, we conclude that observed changes in the tropical sector of South America are due to increased GHGs in this model. The wetting of SESA, however, appears to be mainly caused by ozone depletion.

To go beyond latitude-longitude plots, and associate a precise number to each integration, we compute the modeled precipitation changes over the SESA box, as described in Sect. 2.3 above, for all three perturbed integrations. These changes are plotted in Fig. 5, next to the corresponding observational value from GPCCv4. The light green bars in that figure leave no doubt that, in these CAM3 time-slice integrations, ozone depletion is the cause of modeled wetting of SESA. We hasten to note that the CAM3 amplitude is, roughly, one order of magnitude smaller than GPCCv4. Only in the all-forcings and ozoneonly integrations the modeled change is statistically significant at the $90 \%$ level, whereas the change in GPCCv4 is significant at the $95 \%$ level. Hence, in spite of the model's limitations, the attribution of the modeled changes to ozone depletion is unambiguous in this case.

\subsubsection{The CMAM time-slice integrations}

This result is confirmed by the CMAM time-slice integrations of Sigmond et al. (2010). An important difference between this model and CAM3 is that CMAM is a high-top model, i.e., with a well resolved stratospheric circulation. Two reference CMAM integrations are available: one is a long coupled integration with an active ocean model, the second is an integration of the atmospheric GCM forced with the SSTs taken from the coupled integration. For both of these, the mean precipitation is shown in the top row of Fig. 6, on the left and right respectively. Note that there is no significant difference between these two reference integrations. When compared to GPCCv4 (Fig. 1a), the main differences are a relatively weak monsoon core rainfall, and a southward shift of the ITCZ-related precipitation. For SESA the mean precipitation is slightly overestimated, because the SACZ in this model extends into its northern region.

The lower panels of Fig 6 show the changes resulting from ozone depletion, as obtained from the ozone-only integrations, for the coupled and uncoupled versions of the model (left and right, respectively). It is clear that in CMAM, SESA exhibits mostly wetting under ozone depletion in both versions of the model, but with some differences. In the uncoupled version (Fig. 6d) the changes are closer to the observations, due to the fact that a dipolar pattern with NW-SE orientation is seen in the model between SESA and eastern Brazil, together with a wetting in the northwestern Andes (cf. with Fig. 1b).

In order to directly compare the results from CMAM and CAM3, we show the CMAM precipitation change due to ozone depletion with dark green bars in Fig. 5. Note that 
Fig. 4 Precipitation in the CAM3 time-slice integrations for 1960-1999. a Mean DJF precipitation from the average of the reference and all-forcings integrations, with contours and colors as in Fig. 1a. The other panels show the precipitation changes in the $\mathbf{b}$ all-forcings, c GHG-only and d ozone-only integrations, with contours and colors as in Fig. 1b. Magenta dots in b-d mark grid points where the observed change is significant at the $90 \%$ level according to a $t$ test
Fig. 5 Summary of observed and computed changes in SESA precipitation, for the period 1960-1999. Black the observed change, from the GPCCv4 dataset. Green time-slice changes (CAM3 in dark green and CMAM in light green). Orange CAM3 transient integrations. Red CCSM4/ CMIP5 transient integrations. Blue CCMVal-2 integrations (WACCM in light blue, CMAM in dark blue). The number of ensemble members is shown in parenthesis after the label of each integrations, and the black vertical lines show the complete range of each ensemble. For the 40-member CAM3 ensemble (orange), the interquartile interval is also shown, in grey. See Table 1

\section{CAM3 time-slices - DJF 1960-1999}

(a) all-forcings (1) - Mean

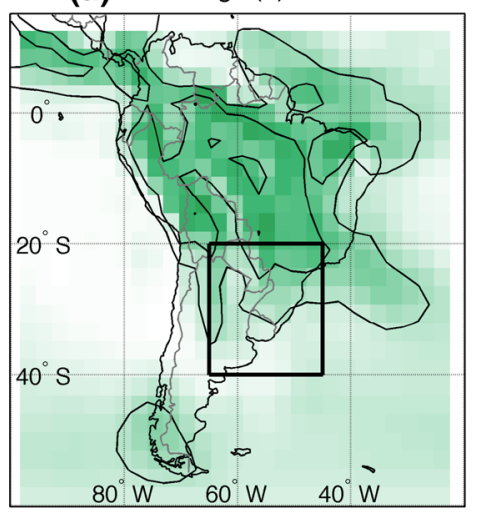

(c) GHG-only (1) - Change

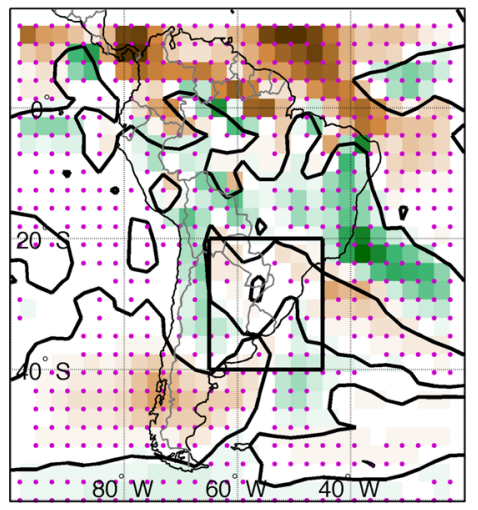

(b) all-forcings (1) - Change

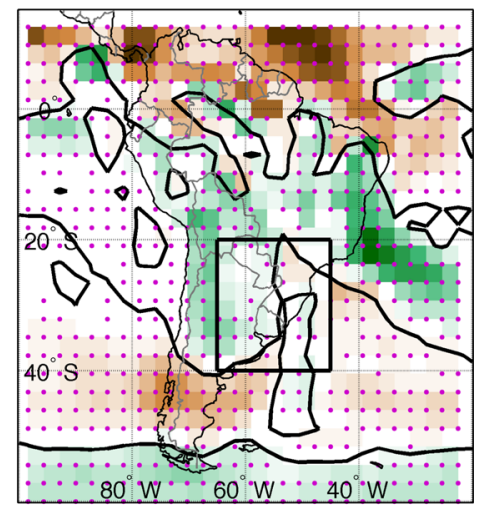

(d) ozone-only (1) - Change

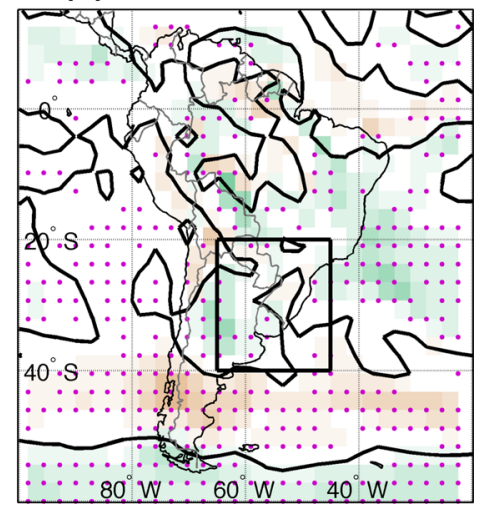

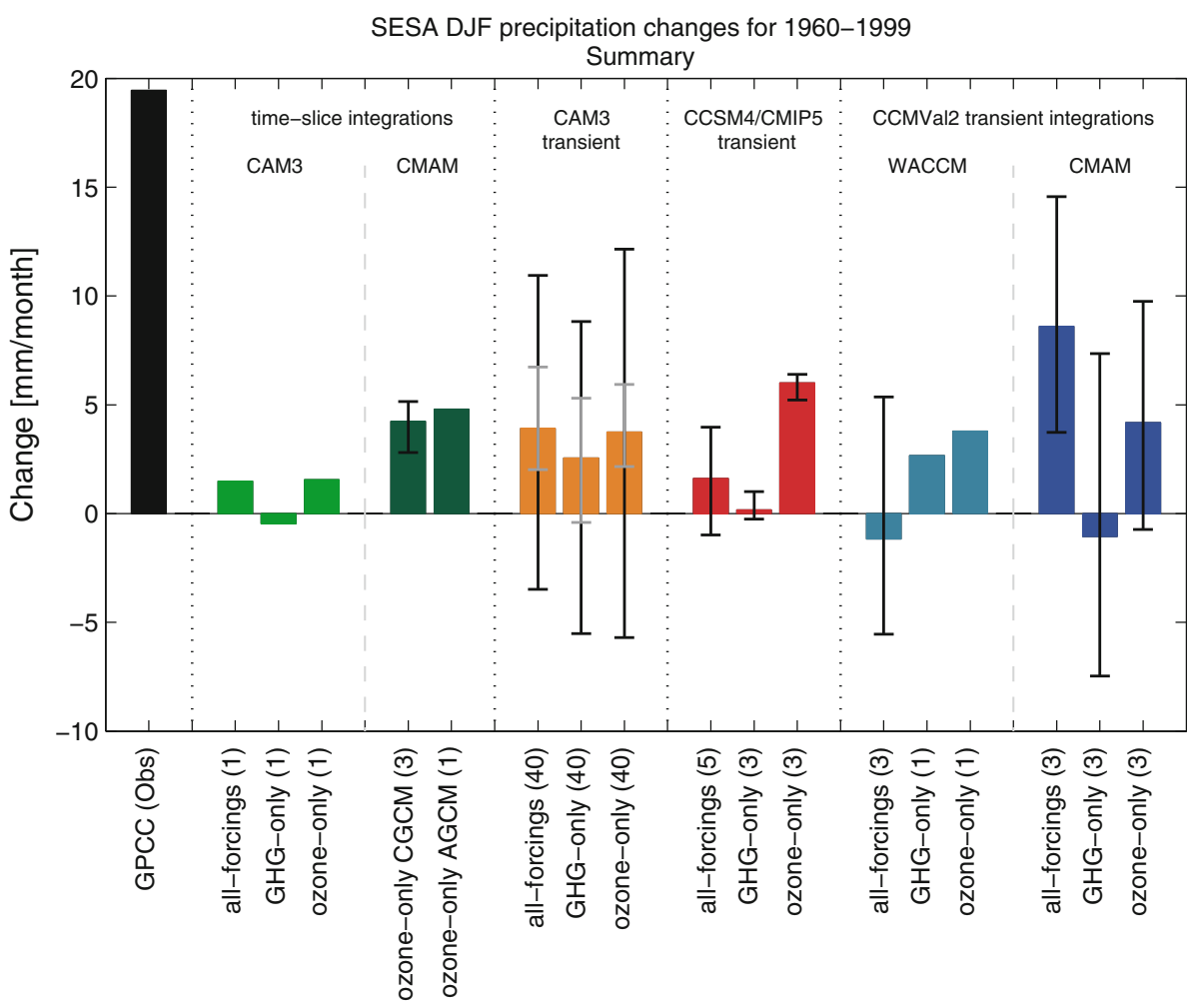


Fig. 6 Precipitation in the CMAM time-slice integrations. Top panels Mean DJF precipitation a CGCM and b AGCM reference integrations, with contours and colors as in

Fig. 1a. Bottom panels changes in precipitation for the c ozoneonly (CGCM) and d ozone-only (AGCM) integrations, with contours and color as in Fig. 1b. In $\mathbf{d}$ the ensemble mean is shown. Magenta dots in the bottom panels mark grid points where the observed change is significant at the $90 \%$ level according to a $t$ test

CMAM time-slices - DJF 1960-1999

(a) $\operatorname{CGCM~(3)~-~Mean~}$

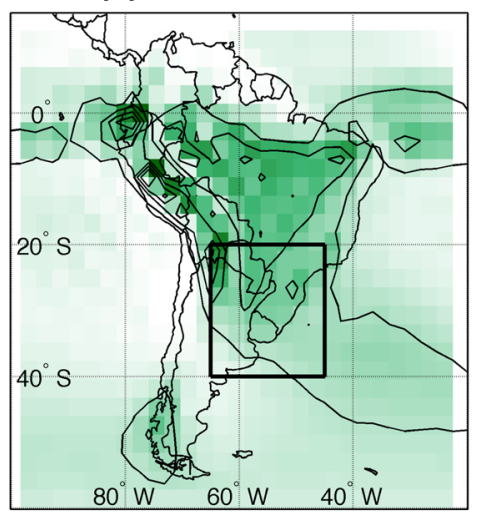

(c) ozone-only CGCM(3)-Change

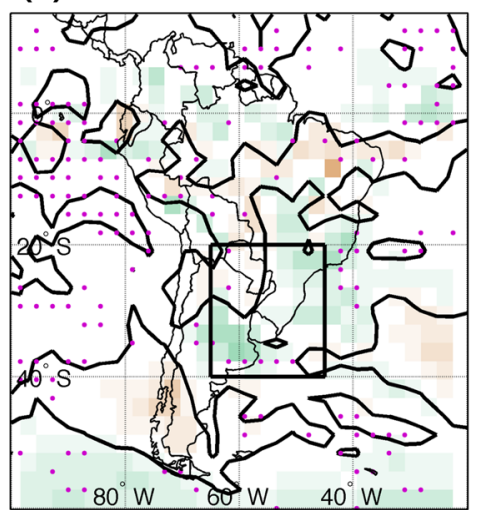

(b) AGCM (1) - Mean

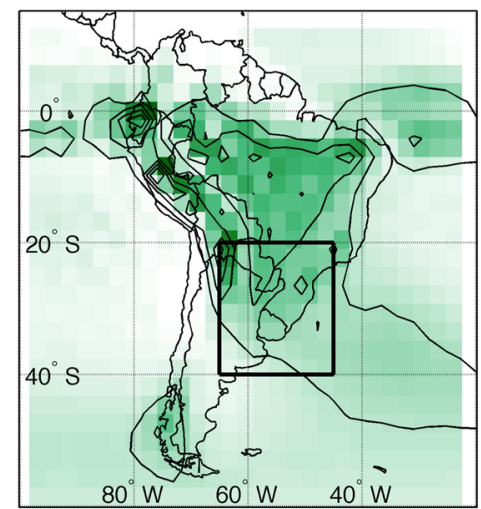

(d) ozone-only AGCM(1)-Change

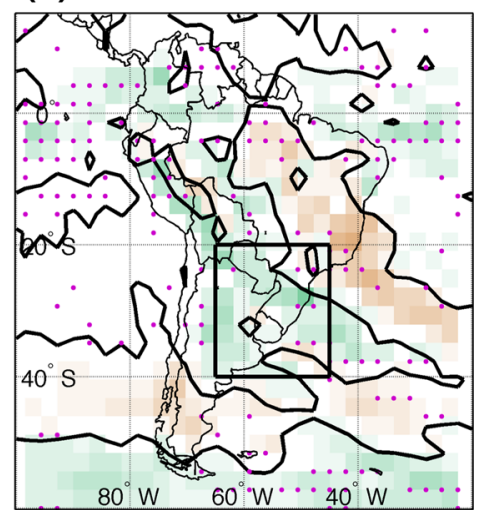

the CMAM changes are larger than the CAM3 changes, for both the coupled and uncoupled integrations, though they are not significant at the $90 \%$ level, and they amount to about one quarter of the observed change. For the CGCM, the superimposed black line shows the scatter among the 3 available integrations, which is smaller than the change itself. In fact, all three coupled integrations show positive precipitation changes over SESA. Therefore, the CMAM results corroborate the above CAM3 results, and show that ozone depletion alone is able to cause modeled wetting over SESA.

\subsection{The CAM3 transient integrations}

We next turn to transient integrations and, again, start from the simplest configuration: the CAM3 atmospheric model. The model was integrated for the period 1960-1999, creating three ensembles - all-forcings, GHG-only and ozoneonly-with 40 members each. The forcing datasets used for these are identical to the ones described in Polvani et al. (2011a), and also used for the time-slice integrations in Sect. 3.2.1 above. Perhaps not surprisingly, the results from these three CAM3 ensembles show a strong similarity with those from the corresponding CAM3 time-slice runs described above. Specifically, Fig. 7a shows that the mean precipitation obtained from the all-forcings ensemble average is almost identical to the one in the time-slice integration shown in Fig. 4a.

Similarly, contrasting Figs. $7 b$ and Fig. 4b, one can see that the precipitation changes over 1960-1999 in the allforcings ensemble are also similar to the time-slice ones, with wetting over SESA as observed, but with changes in eastern Brazil and tropical South America opposite in sign to the observations. Unlike the time-slice integrations, however, in the case of the GHG-only ensemble (Fig. 7c), wetting is observed over SESA, although less generalized than in the ozone-only ensemble (Fig. 7d). In this last case, the dipolar structure in the change between SESA and eastern Brazil is also present, though somewhat weaker than in the observations (Fig. 1b).

These transient CAM3 results are summarized by the orange bars in Fig. 5, which show wetting over SESA for the 1960-1999 period in all three ensembles, although weaker than the observations. Note that the GHG-only ensemble (central orange bar), explains a smaller positive change than the ozone-only ensemble (rightmost bar). Note also that while the spread among the 40 members is quite large in all cases (black lines), the interquartile range (gray 
Fig. 7 Precipitation in the CAM3 transient integrations. a Time mean DJF precipitation for the all-forcings ensemble, with contours and colors as in Fig. 1a. The other panels show the ensemble mean changes in precipitation in the $\mathbf{b}$ allforcings, c GHG-only and d ozone-only ensembles, with contours and colors as in

Fig. 1b. The magenta dots in (b-d) indicate grid points with the trend of the ensemble mean is significant at the $90 \%$ level according to a Mann-Kendall test. The number of ensemble members is indicated in the title of each panel

CAM3 transient runs - DJF 1960-1999

(a) all-forcings (40) - Mean

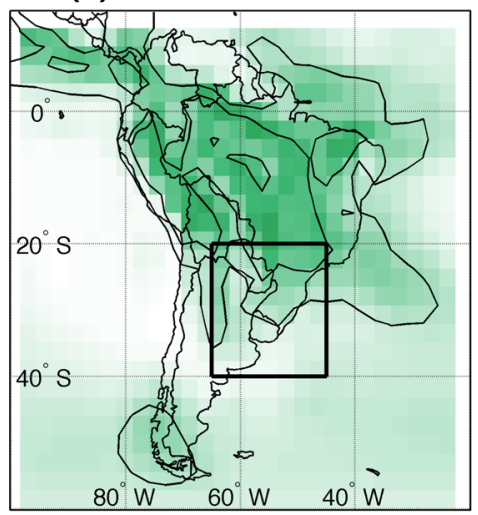

(c) GHG-only (40) - Change

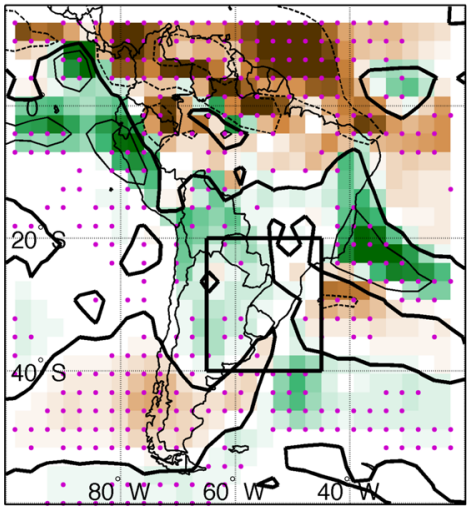

(b) all-forcings (40) - Change

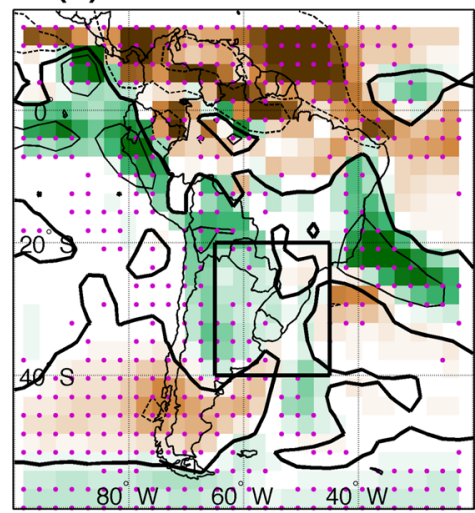

(d) ozone-only (40) - Change

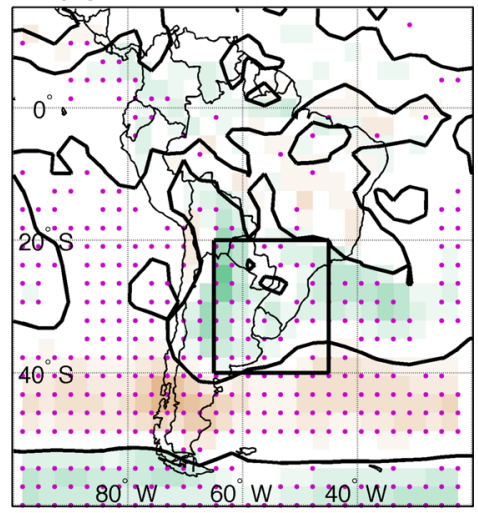

lines)_containing the central $50 \%$ of the ensemble members - encompasses only positive values for the allforcings and ozone-only ensembles, whereas it includes both negative and positive values in the GHG-only case. Furthermore, we find that the ozone-only ensemble mean alone is significant at the 90 and $95 \%$ levels. This would suggest that ozone-depletion might be a more important forcing for SESA precipitation changes than GHG increases.

\subsection{The CCSM4/CMIP5 transient integrations}

This conclusion is greatly reinforced by the next set of transient model integrations we analyzed. These were performed as part of the CMIP5 project with CCSM4. This low-top, atmosphere-ocean-land-sea-ice model is a very recent version of NCAR's coupled climate model and, as such, can be thought of as a state-of-the-art IPCC-class CGCM. Three ensembles are available: all-forcings, GHGonly and ozone-only. Unfortunately, these ensembles are relatively small (only a few members each), but still allow us to get a sense of the magnitude of the internal variability (Deser et al. 2012).
The 1960-1999 mean precipitation field for the allforcings CCSM4/CMIP5 ensemble is shown in Fig. 8a. The largest difference with the observations (Fig. 1a) is that the model merges the monsoon core and the ITCZ over the Atlantic, with a local maximum too far to the east, near northeastern Brazil. In addition, this model shows some indication of a double ITCZ problem in both tropical basins.

The corresponding changes are shown in Fig. 8b. These patterns are quite similar to the observations (Fig. 1b), though apparently shifted south, which might be due to an overall model bias. Nevertheless, more than half of the SESA box exhibits clear wetting, and the eastern coast of Brazil shows drying. For the GHG-only ensemble (Fig. 8c), the signal over SESA is highly mixed, with large cancellation suggesting a very small overall SESA change. In contrast, the ozone-only ensemble (Fig. 8d) shows a very clear wetting over all of SESA.

The precipitation changes for these integrations, averaged over the SESA box, are indicated by the red bars in Fig. 5. While the changes are positive for all three ensembles, they are much larger in the ozone-only case. In fact, the changes for the ozone-only ensemble are positive for each member, whereas for the GHG ensemble they are 
Fig. 8 As in Fig. 7, but for the CCSM4/CMIP5 transient integrations

\section{CCSM4/CMIP5 transient runs - DJF 1960-1999}

(a) all-forcings (5) - Mean

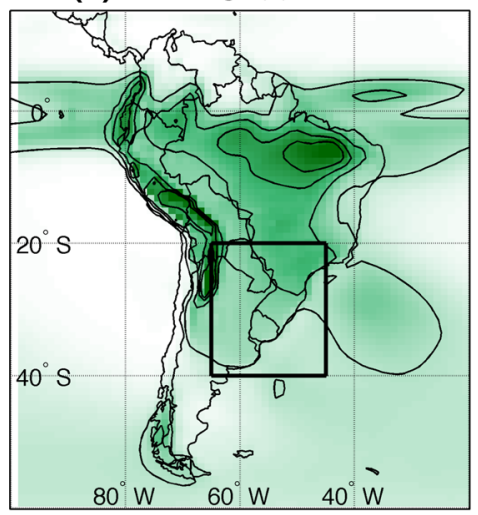

(c) GHG-only (3) - Change

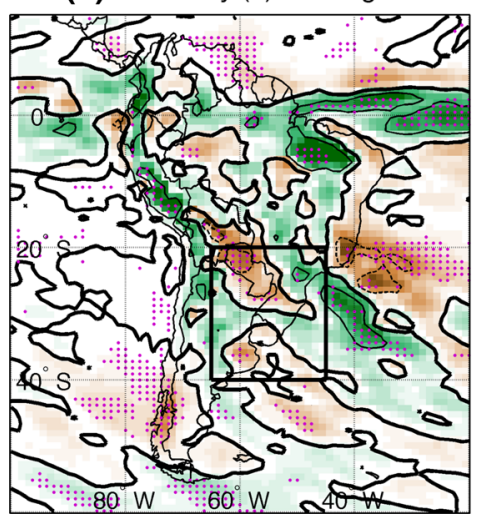

(b) all-forcings (5) - Change

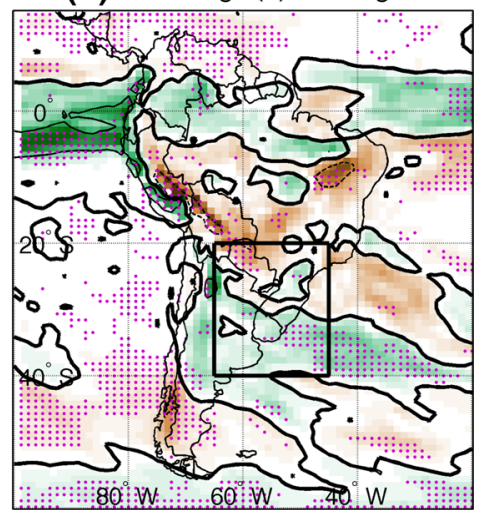

(d) ozone-only (3) - Change

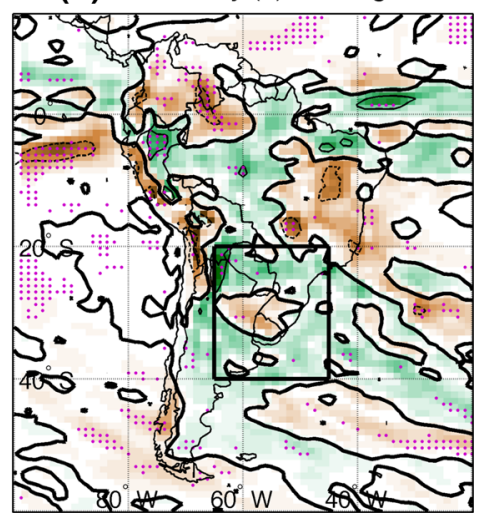

negative in some cases. We acknowledge that these singleforcing integrations have small ensembles (only 3 members each), which probably explains the small spread in comparison with the all-forcings ensemble. While none of the ensemble mean changes are statistically significant at the $90 \%$ level, these results are in agreement with the ones obtained from the previous analysis, and together provide compelling evidence that ozone depletion has been an important forcing of the SESA precipitation trend.

\subsection{The CCMVal-2 transient integrations}

The high-top models discussed in this and the next section further corroborate this possibility. These models include, in addition to a full representation of stratospheric dynamics, interactive stratospheric chemistry. Therefore, only surface concentrations of ozone-depleting substances are specified in these model, instead of the entire latitude-height ozone fields. We analyze here two such models, whose ensembles were performed for the CCMVal-2 project.

\subsubsection{The WACCM transient integrations}

The WACCM model is the simpler of the two: it is a hightop atmosphere only model with specified SSTs. Fig. 9a shows the mean 1960-1999 SESA precipitation, for the allforcings ensemble. One can see that the model locates the monsoon maximum to the northeast of its observed climatological position (Fig. 9b). The mean values observed over the SESA box, however, are consistent with the observations. The precipitation changes in the all-forcings ensemble (Fig. 9b) show a wetting sector around SESA positioned slightly to the south, whereas the tropical region shows changes consistent with observations.

The key point of the figure comes from comparing the changes in the GHG-only (Fig. 9c) and ozone-only (Fig. 9d) sets. These suggest that most of the simulated precipitation increase in the subtropics (and hence SESA) in the all-forcings integrations are due to the ozone forcing, whereas the changes observed in the more tropical sector are due to a combination of both forcings.

The light blue bars in Fig. 5 summarize these findings. Note that the mean SESA change in the all-forcings ensemble is slightly negative, due to this model's bias in the positioning of the wetting band. However, the spread among the members is very large, and does encompass large positive changes. Unfortunately only a single member is available for the single-forcing integrations. In addition, none of the ensemble mean changes are statistically significant at the $90 \%$ level. With those caveats, we 
Fig. 9 As in Fig. 7, but for the WACCM transient integrations

WACCM CCMVal-2 transient runs - DJF 1960-1999

(a) all-forcings (3) - Mean

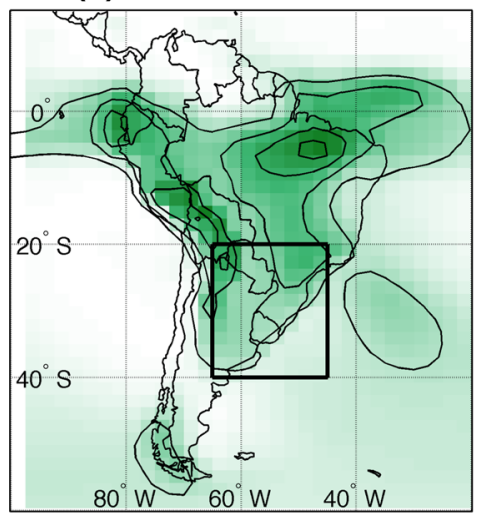

(c) GHG-only(1) - Change

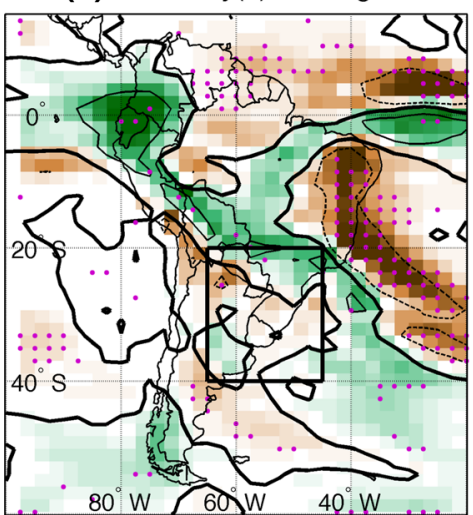

(b) all-forcings (3) - Change

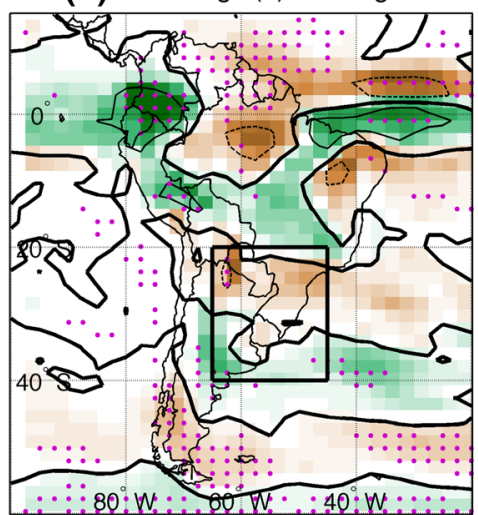

(d) ozone-only(1) - Change

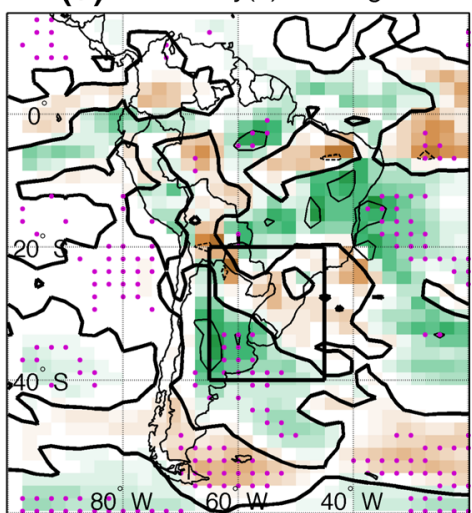

nonetheless observe that precipitation changes are larger in the ozone-only than in the GHG-only integrations for this model as well.

\subsubsection{The CMAM transient integrations}

The last piece of evidence implicating ozone depletion on SESA precipitation changes comes from the most complex model in this study. The version of CMAM analyzed here consist of a stratosphere resolving (high-top) atmospheric model, with interactive stratospheric chemistry, and coupled to an interactive ocean model. The integrations discussed here have been carefully documented in the literature (McLandress et al. 2010, 2011), and we focus uniquely on SESA precipitation changes over the period 1960-1999.

Because this version of CMAM is run at a somewhat degraded horizontal resolution (T31, corresponding to a $6^{\circ}$ latitude-longitude grid spacing), this model is unable to correctly reproduce many features of the monsoon season, as can be seen in Fig. 10a. There is a hint of a SACZ-like feature, but without a clear distinction from the monsoon core. In addition, precipitation in the SESA box has a positive bias due to the fact that the model overestimates the rainfall associated with the Andes, with a strong maximum reaching northern Argentina.

Nonetheless, the all-forcings ensemble mean (Fig. 10b) shows a clear precipitation increase over SESA, also found in every member of the ensemble (not shown). In fact, as one can see from the dark blue bars in Fig. 5, these CMAM integrations show the largest computed SESA precipitation changes of all the models we have analyzed.

From the single-forcing experiments, it is clear that a large precipitation increase occurs in the ozone-only ensemble (Fig. 10d), whereas the GHG-only (Fig. 10c) ensemble exhibits mostly negative changes over SESA, albeit with a very large spread among its integrations (Fig. 5). Notice, in contrast, that the mean precipitation changes are positive for the ozone-only set, with only one member showing slight drying over SESA. Only the all-forcings ensemble mean change is significant at the $90 \%$ level.

In this model, as in others examined above, the evidence for the role of ozone depletion is not conclusive. It is, however, the accumulation of such evidence over a large array of models (with very different complexity) that imparts robustness to the key result of this paper. 
Fig. 10 As in Fig. 7, but for the CMAM transient integrations

CMAM CCMVal-2 transient runs - DJF 1960-1999

(a) all-forcings (3) - Mean

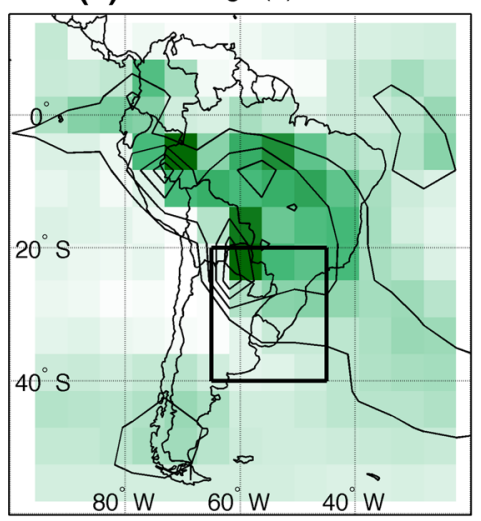

(c) GHG-only (3) - Change

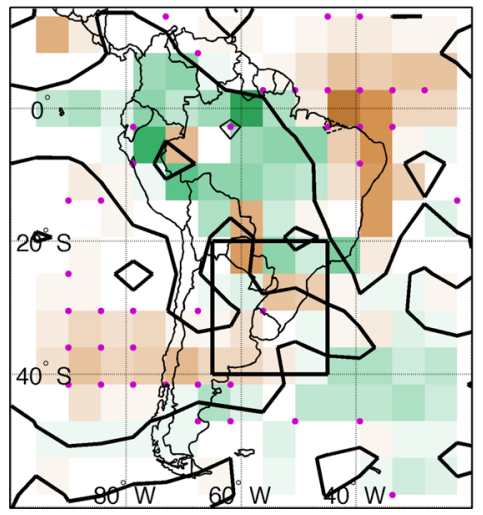

(b) all-forcings (3) - Change

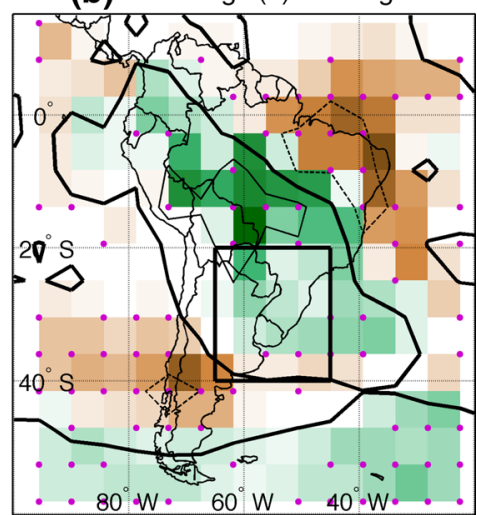

(d) ozone-only (3) - Change

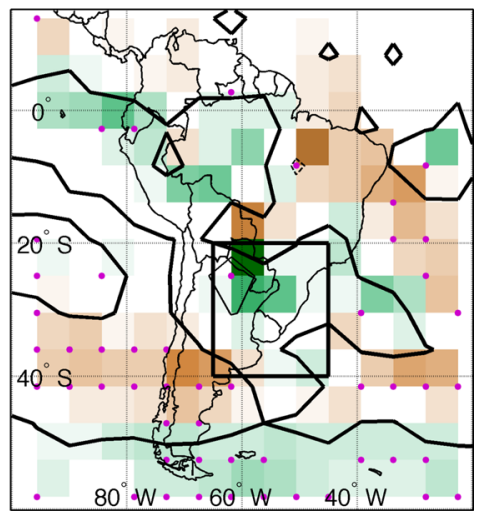

\section{The dynamics of ozone-depletion induced precipitation changes}

Additional evidence can be offered from the dynamical mechanism associated with the precipitation changes that result from imposing ozone depletion in these integrations. We illustrate the mechanism with the 40-member CAM3 transient ensemble, as we have computed these ourselves, and therefore all the variables are easily available to construct a clear picture.

Using output from the ozone-only CAM3 transient integrations, we summarize the mechanism in Fig. 11. Changes in the $200 \mathrm{hPa}$ zonal mean zonal wind over the 1960-1999 period, computed from the linear trend, are shown in Fig. 11a. Note the clear blue/red dipole in the southern midlatitudes, corresponding to the poleward displacement of the extratropical westerly jet, which has now been widely documented to follow from ozone-depletion. In particular, within the SESA box, the zonal wind change is characterized by an anomalous cyclonic pattern. Accompanying this circulation pattern, one finds increased vertical motion, as demonstrated by the green colors within SESA in Fig. 11b.

The link between this increased upwelling and the midlatitude jet shift can be seen in the red and blue contours in the top panel of Fig. 11c: these contours represent the changes in the monthly-mean, transient eddy momentum fluxes for a limited longitudinal range in the vicinity of Southern South America. Specifically, the momentum flux divergence centered around $35^{\circ} \mathrm{S}$ in the upper troposphere is balanced by an anomalous southward upper tropospheric flow, which in turn forces upward motion between $20^{\circ} \mathrm{S}$ and $35^{\circ} \mathrm{S}$ (as shown by the vertical velocity changes in green shades). Consistent with this, the bottom panel of Fig. 11d shows that this latitudinal band exhibits increases both in vertically integrated precipitable water (green curve) and in precipitation itself (blue bars). This mechanism is exactly the one proposed in Kang et al. (2011) to explain the ozone-induced average wetting of the SH subtropical band. As in their assessment, these results show that the SESA precipitation changes due to ozone depletion in these integration are driven by circulation changes rather than thermodynamic ones.

\section{Summary and conclusions}

The impact of stratospheric ozone depletion on precipitation in South Eastern South America was analyzed in a 
Fig. 11 Changes in dynamical fields in CAM3 transient ozoneonly ensemble, obtained from the linear trend for the period 1960-1999. The top panels show the changes in a zonal wind at $200 \mathrm{hPa}$ (in $\mathrm{m} / \mathrm{s}$ ) and b the vertical velocity $\omega$ at $700 \mathrm{hPa}$ (in $\mathrm{Pa} / \mathrm{s}$ ). c Vertical cross-sections from a limited longitudinal average $\left(120^{\circ} \mathrm{W}-\right.$ $20^{\circ} \mathrm{W}$ ) for $\omega$ (shading) and $U^{\prime} V^{\prime}$ (contours). d Compares the changes in precipitation ( $\mathrm{mm} / \mathrm{month}$, blue bars) and vertically integrated precipitable water ( $\mathrm{mm}$, green curve) for the same limited zonal average
CAM3 ozone-only (40) - DJF Changes for 1960-1999 (a) $\cup 200 \mathrm{hPa}$

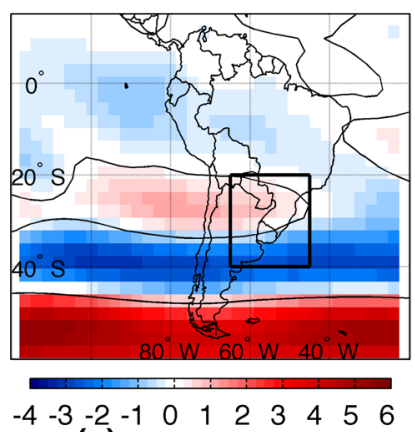

(b) Omega $700 \mathrm{hPa}$

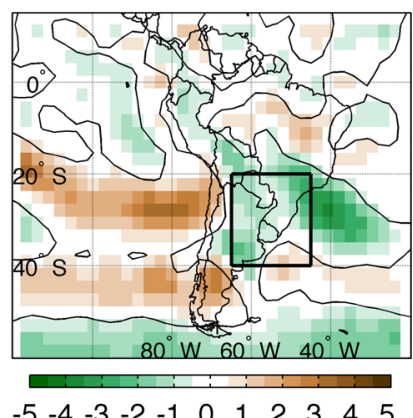

(c) Zonal Mean change in Omega (shading) and U' V' (contours)

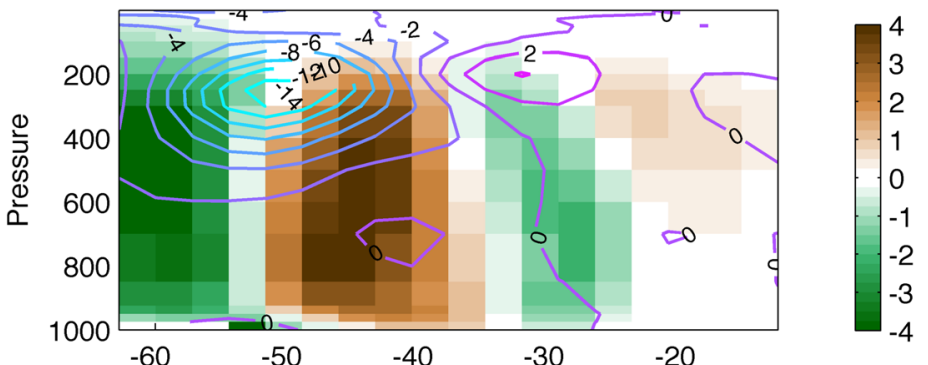

(d) Precipitation and vertically integrated Precipitable Water

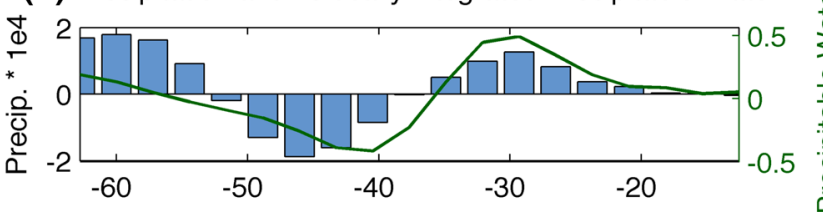

hierarchy of numerical experiments with different general circulation (both AGCMs and CGCMs) and climatechemistry models. All the GCMs considered in this study underestimate the precipitation change over SESA but, as we have illustrated with the CMIP3 and CMIP5 ensembles, this is a widespread deficiency of all recent-generation climate models.

That said, we have found a unanimous agreement across the ensemble means of all model integrations we analyzed: specifying ozone depletion alone as a forcing agent results in a clear increase in SESA precipitation. Furthermore, the same model integrations show that, for the period 1960-1999, increasing GHGs cause either small or negative changes in SESA precipitation-unlike ozone-depletion, the GHG forcing does not show a consensus among the models. Taken together, these results suggest that stratospheric ozone depletion has significantly contributed to the observed wetting in the region during 1960-1999, and that its impact has been as large as, and possibly larger, than the one caused by increasing GHGs.

The mechanism proposed by Kang et al. (2011), which we have confirmed with the new integrations shown here, only offers an explanation for the zonal mean changes. A more detailed dynamical analysis is needed to understand the zonal asymmetries associated with the ozone-induced precipitation changes over South America and the surrounding oceans. In particular, topographic features in the region and their influence on the mean flow are likely to be important, and this would require the use of higher resolution or regional climate models.

The results of this work are of particular relevance for the coming decades, since the ozone layer is predicted to recover by the second half of the 21st Century (WMO 2010). As the ozone hole closes, the effects of ozone recovery will oppose and possibly overwhelm the effects of increasing GHGs, notably on the position of the midlatitude jet, the extent of the Hadley circulation, and the associated subtropical precipitation, as documented in a number of recent studies (Son et al. 2010; Arblaster et al. 2011; McLandress et al. 2011; Polvani et al. 2011b). Therefore, if the recently observed increase in SESA precipitation changes is partly caused by ozone-induced circulation changes, as we are here suggesting, we might infer that precipitation will stabilize or, possibly, decrease in the coming decades, as a consequence of ozone recovery. Foreseeing such a scenario could have a significant impact in the region's economic and agricultural strategies, which are of great relevance to the World's grain and food productions. 
Acknowledgments PG and RS were supported by NSF EaSM award 1049066 (Multi-scale Climate Information for Agricultural Planning in Southeastern South America for Coming Decades). RS was also supported by NOAA award NA10OAR4310137 (Global Decadal Hydroclimate Change and Variability, GloDecH). LMP is supported by a grant from the NSF to Columbia University. We acknowledge the World Climate Research Programme (WCRP) Working Group on Coupled Modeling; the US Department of Energy's Program for Climate Model Diagnosis and Intercomparison (CMIP) provides coordinating support and led development of software infrastructure in partnership with the Global Organization for Earth System Science Portals. For the chemistry-coupled models, we thank the Chemistry-Climate Model Validation (CCMVal-2) Activity for the WCRP SPARC (Stratospheric Processes and their Role in Climate) project for organizing and coordinating the model data analysis activity. Special thanks to John Fyfe and Michael Sigmond, for allowing us to use their data for the CMAM time-slice integrations.

Open Access This article is distributed under the terms of the Creative Commons Attribution License which permits any use, distribution, and reproduction in any medium, provided the original author(s) and the source are credited.

\section{References}

Arblaster JM, Meehl GA, Karoly DJ (2011) Future climate change in the Southern Hemisphere: competing effects of ozone and greenhouse gases. Geophys Res Lett 38:L02701. doi:10.1029/ 2010GL045384

Barros VR, Doyle ME, Camilloni IA (2008) Precipitation trends in southeastern South America: relationship with ENSO phases and with low-level circulation. Theor Appl Climatol 93:19-33

Chan SC, Behera SK, Yamagata T (2008) Indian Ocean Dipole influence on South American rainfall. Geophys Res Lett 35:L14S12. doi:10.1029/2008GL034204

Cionni I, Eyring V, Lamarque JF, Randel WJ, Stevenson DS, Wu F, Bodeker GE, Shepherd TG, Shindell DT, Waugh DW (2011) Ozone database in support of CMIP5 simulations: results and corresponding radiative forcing. Atmos Chem Phys 11:11267-11292

Collins WD et al (2006) The community climate system model version 3 (CCSM3). J Clim 19:2122-2143

Deser C, Phillips A, Bourdette V, Teng H (2012) Uncertainty in climate change projections: the role of internal variability. Clim Dyn 38:527-546. doi:10.1007/s00382-010-0977-x

Eyring V et al (2012) Long-term changes in tropospheric and stratospheric ozone and associated climate impacts in CMIP5 simulations. J Geophys Res. doi:10.1002/jgrd.50316

Garcia RR et al (2007) Simulation of secular trends in the middle atmosphere, 1950-2003. J Geophys Res 112:D09301. doi: 10.1029/2006JD007485

Gent PR et al (2011) The Community climate system model version 4. J Clim 24:4973-4991. doi:10.1175/2011JCLI4083.1

Gillett N, Thompson DWJ (2003) Simulation of recent Southern Hemisphere climate change. Science 302:2730-275. doi: 10.1126/science. 1087440

Gonzalez PLM, Goddard L, Greene AM (2012) Twentieth-century summer precipitation in South Eastern South America: comparison of gridded and station data. Int J Climatol. doi:10.1002/ joc. 3633

Gerber EP et al (2012) Assessing and understanding the impact of stratospheric dynamics and variability on the earth system. Bull Am Meteor Soc 93:845-859. doi:10.1175/BAMS-D-11-00145.1
Haylock MR et al (2006) In total and extreme South American rainfall in 1960-2000 and links with sea surface temperature. J Clim 19:1490-1512

$\mathrm{Hu}$ Y, Xia Y, Fu Q (2011) Tropospheric temperature response to stratospheric ozone recovery in the 21 st century. Atmos Chem Phys 11:7687-7699. doi:10.5194/acp-11-7687-2011

Kang SM, Polvani LM, Fyfe JC, Sigmond M (2011) Impact of polar ozone depletion on subtropical precipitation. Science 332: 951-954

Kendall MG (1975) Rank correlation methods. Griffin, London

Lamarque JF et al (2010) Historical (1850-2000) gridded anthropogenic and biomass burning emissions of reactive gases and aerosols: methodology and application. Atmos Chem Phys 10:7017-7039. doi:10.5194/acp-10-7017-2010

Lee S, Feldstein SB (2013) Detecting ozone- and greenhouse-gasdriven wind trends with observational data. Science 339(6119):563-567

Liebmann B et al (2004) An observed trend in central South American precipitation. J Clim 17:4357-4367. doi:10.1175/3205.1

Mann HB (1945) Nonparametric tests against trend. Econometrica $13: 245-259$

McLandress C, Jonsson AI, Plummer DA, Reader MC, Scinocca JF, Shepherd TG (2010) Separating the dynamical effects of climate change and ozone depletion. Part I: Southern Hemisphere stratosphere. J Clim 23:5002-5020. doi:10.1175/2010JCLI3586.1

McLandress C, Shepherd TG, Scinocca JF, Plummer DA, Sigmond M, Jonsson AI, Reader MC (2011) Separating the dynamical effects of climate change and ozone depletion. Part II: Southern Hemisphere Troposphere. J Clim 24:1850-1868. doi:10.1175/ 2010JCLI3958.1

Morgenstern $\mathrm{O}$ et al (2010) Review of present-generation stratospheric chemistry-climate models and associated external forcings. J Geophys Res 115:D00M02. doi:10.1029/2009JD013728

Meehl G, Covey C, Delworth T, Latif M, McAvaney B, Mitchell JFB, Stouffer RJ, Taylor KE (2007) The WCRP CMIP3 multimodel dataset: a new era in climate change research. Bull Am Meteor Soc 88:1383-1394

Perlwitz J, Pawson S, Fogt RL, Nielsen JE, Neff WD (2008) Impact of stratospheric ozone hole recovery on Antarctic climate. Geophys Res Lett 35:L08714. doi:10.1029/2008GL033317

Polvani LM, Waugh DW, Correa JGP, Son SW (2011a) Stratospheric ozone depletion: the main driver of 20th Century atmospheric circulation changes in the Southern Hemisphere. J Clim 24:795-812. doi:10.1175/2010JCLI3772.1

Polvani LM, Previdi M, Deser C (2011b) Large cancellation, due to ozone recovery, of future Southern Hemisphere atmospheric circulation trends. Geophys Res Lett 38:L04707. doi: 10.1029/2011GL046712

Previdi M, Polvani LM (2012) Comment on "Tropospheric temperature response to stratospheric ozone recovery in the $21 \mathrm{st}$ Century" by Hu et al. (2011). Atmos Chem Phys 12:4893-4896 doi:10.5194/acp-12-4893-2012

Randel WJ, Wu F (2007) A stratospheric ozone profile data set for 1979-2005: variability, trends, and comparisons with column ozone data. J Geophys Res 112:D06313. doi:10.1029/ 2006JD007339

Rayner NA, Parker DE, Horton EB, Folland CK, Alexander LV, Rowell DP, Kent EC, Kaplan A (2003) Global analyses of sea surface temperature, sea ice, and night marine air temperature since the late nineteenth century. J Geophys Res 108:4407. doi: 10.1029/2002JD002670

Ropelewski CF, Halpert MS (1996) Quantifying southern oscillationprecipitation relationships. J Clim 9:1043-1959

Schneider U, Fuchs T, Meyer-Christoffer A, Rudolf B (2008) Global precipitation analysis products of the GPCC. Global Precipitation climatology, Centre Tech Rep, 12 pp 
Scinocca JF, McFarlane NA, Lazare M, Li J, Plummer D (2008) The CCCma third generation AGCM and its extension into the middle atmosphere. Atmos Chem Phys 8:7055-7074

Seager R, Naik N, Baethgen W, Robertson A, Kushnir Y, Nakamura J, Jurburg S (2010) Tropical oceanic causes of interannual to multidecadal precipitation variability in Southeast South America over the past century. J Clim 23:5517-5539. doi:10.1175/ 2010JCLI3578.1

Sigmond M, Fyfe JC, Scinocca JF (2010) Does the ocean impact the atmospheric response to stratospheric ozone depletion. Geophys Res Lett 37:L12706. doi:10.1029/2010GL043773

Silvestri G, Vera C (2003) Antarctic oscillation signal on precipitation anomalies over southeastern South America. Geophys Res Lett 30:2115. doi:10.1029/2003GL018277

Smith R et al (2010) The parallel ocean program (POP) reference manual. Los Alamos National Lab Technical Report, p 141

Son S-W, Polvani LM, Waugh DW, Akiyoshi H, Garcia R, Kinnison D, Pawson S, Rozanov E, Shepherd TG, Shibata K (2008) The impact of stratospheric ozone recovery on the southern hemisphere westerly jet. Science 320:1486-1489. doi:10.1126/ science.1155939

Son S-W, Tandon NF, Polvani LM, Waugh DW (2009) Ozone hole and Southern Hemisphere climate change. Geophys Res Lett 36:L15705. doi:10.1029/2009GL038671
Son S-W, Gerber EP, Perlwitz J, Polvani LM, Gillett N, CCMVal Coauthors (2010) The impact of stratospheric ozone on Southern Hemisphere circulation changes: a multimodel assessment. J Geophys Res 115:D00M07. doi:10.1029/2010JD014271

SPARC CCMVal (2010) SPARC CCMVal report on the evaluation of chemistry-climate models. In: Eyring V, Shepherd TG, Waugh DW (eds) SPARC Report No 5, WCRP-X, WMO/TD-No. $\mathrm{X}$. Available at http://www.atmosp.physics.utoronto.ca/SPARC

Taylor KE, Stouffer RJ, Meehl GA (2012) An overview of CMIP5 and the experiment design. Bull Am Meteor Soc 93:485-498

Thompson DWJ, Wallace JM, Hegerl GC (2000) Annular modes in the extratropical circulation. Part II: trends. J Clim 13:1018-1036

Thompson DWJ, Solomon S (2002) Interpretation of recent Southern Hemisphere climate change. Science 296:895-899

Viglizzo E, Frank FC (2006) Ecological interactions, feedbacks, thresholds and collapses in the Argentine Pampas in response to climate and farming during the last century. Quat Int 158: $122-126$

WMO (World Meteorological Organization) (2011) Scientific assesment of ozone depletion: 2010. Global ozone research and monitoring project, Report No 52, Geneva, Switzerland, 516 pp

Zhou J, Lau K (2001) Principal modes of interannual and decadal variability of summer rainfall over South America. Int J Climatol 21:1623-1644 